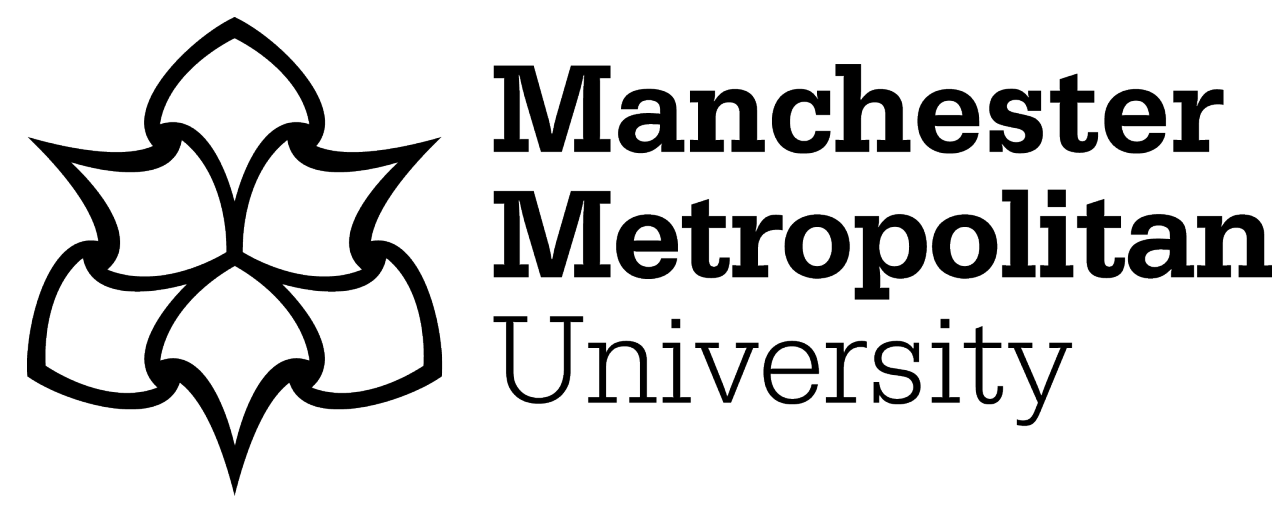

Tan, Kai Syng ORCID logoORCID: https://orcid.org/0000-0002-4491-7166 (2016) Tough Ultramarathons and Life on the Run. Transfers, 6 (3). pp. 130-137. ISSN 2045-4813

Downloaded from: https://e-space.mmu.ac.uk/624485/

Version: Accepted Version

Publisher: Berghahn Books

DOI: https://doi.org/10.3167/trans.2016.060311

Please cite the published version 


\section{MOBILITY AND ART}

\section{Tough Ultramarathons and Life on the Run}

\section{Kai Syng Tan, Leeds College of Art}

What are the ways in which running-the popular exercise, the locomotion, the etymology of the word and its rich idiomatic expressions-can be activated as a metaphor and method to think and talk about the so-called migrant crisis and, more generally, how people cross borders today? With phrases like "life on the run," "letting your imagination run riot," "running away," and "running for your life," how can the poetic processes of running act as a toolkit of resistance as we move about, to "run against" the status quo, in refusing to "take things lying down," and letting things "come to a standstill"? What are the new frontiers for the twenty-first-century mobile citizen? What does it mean to be a political, digital, existential, and intellectual exile, either forced or voluntary? How can artists make and disseminate work on the move, and reflect on and complicate this life on the move?

The above are a few of the overlapping-and contradictory-questions behind this exhibition of eight works put together for Transfers. I created the images over the past six years as a (mediocre) runner, mongrel, and one of 230 million people around the world who live outside the country in which they were born. Artist Ai Wei Wei has created artworks responding to the current refugee situation in Europe; yet more voices from the cultural sectors could help enrich the discussion dominated by politicians, journalists, scholars, and "Nimbies" - people who oppose something they perceive as detrimental to their immediate reality; "not in my backyard").

One of the works here, Certainly the Toughest UltraMarathon of Your Life, was created as thousands of refugees made a $135 \mathrm{~km}$ trek from Hungary to Austria last summer. Based on a map of Africa-Europe, this artist's map shows the European "warriors" making "heroic" maneuvers-except that instead of Tough Mudder races and other man-made adventures, they are making perilous crossings over the sea (depicted in Figure 1 in a deep red tone) and jumping over (or crawling under) physical (and metaphorical) barbed-wired hurdles across different "challenges" marked out in gaudy colors for easy identification for the (often middle-class) participants who would have paid (quite) a bit of money to take part in such "first world" rituals of voluntary mass suffering. The intention of such a mash-up is to provoke viewers to interrogate 
their own hypocrisies and to critique the lazy demonization of migrants by mainstream media and Nimbies. The map resembles a publicity poster for the next endurance "event," but in a tone that is mocking, grotesque, paradoxical, self-conscious, caricatural, and over the top. There are searchlights, the colors are plastic, the figures ready-made athletic poses downloaded (royalty-free!) and repeated, digitally, endlessly, decoratively, vainly, in vain.

This set of images constitute part of a body of installations, artistic interventions, and other practice-related research investigating running beyond its traditional fields of sport or exercise and as a creative and critical apparatus to reimagine the world around us, with a perspective on the body-mind matrix from the ancient Chinese tradition of Daoism (Taoism), which is often missing in contemporary, mainstream Western discourses of mobility. The running-centered works are, in turn, part of a portfolio covering twenty years that explores the body and mind in motion as a sight and site of autonomy across terrains urban, historical, digital, political, and imaginary. Modes of

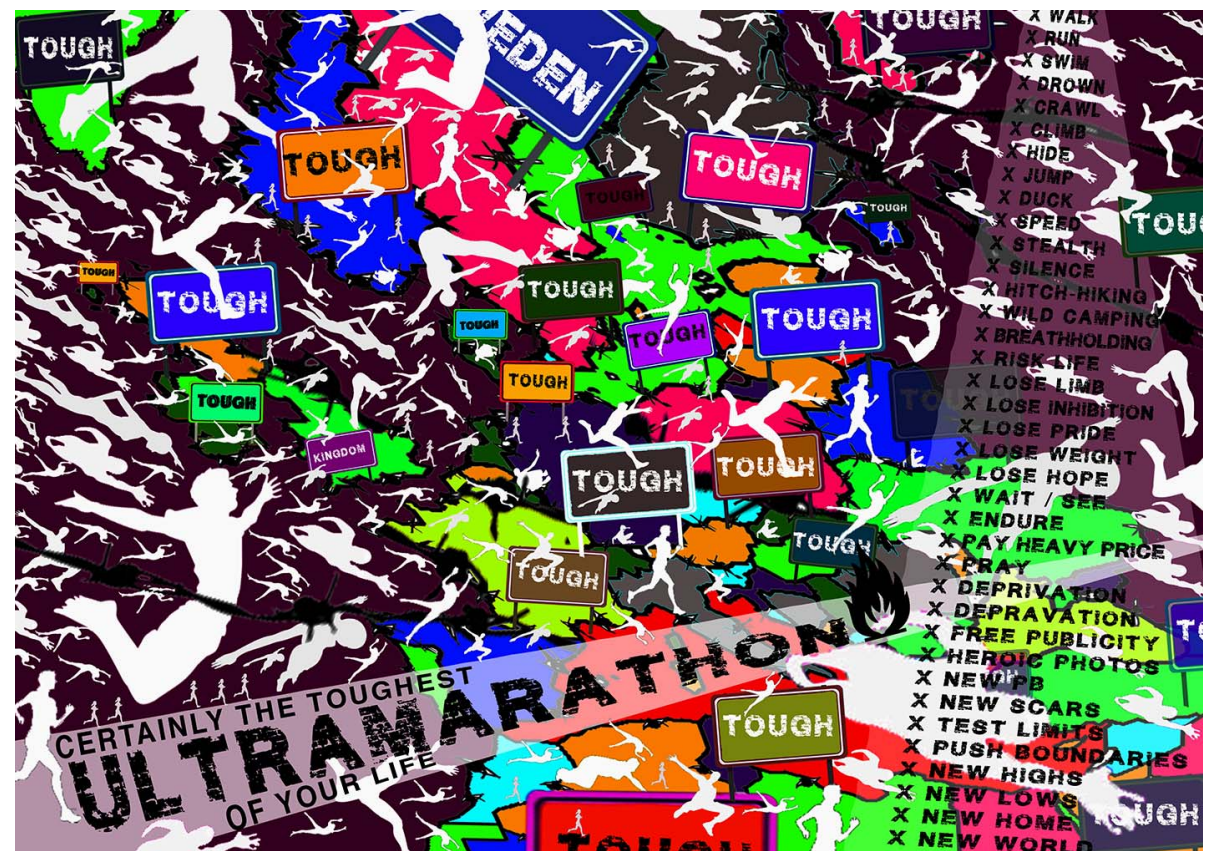

Figure 1: Certainly the Toughest Marathon of Your Life! 2015, digital, size variable. By drawing a satirical parallel between the grueling (and exorbitant) journeys that migrants undertake to seek asylum in Europe, with the grueling (and exorbitant) endurance races that niche but expanding groups of people from the "first world" subject themselves to in the name of fitness, adventure, or self-fulfillment, this image critiques the demonization of migrants by mainstream media and Nimbies. Premiered at the Being Human Festival. Acquired by Leeds College of Art and currently on display. Image: Kai Syng Tan. 
mobilities that I have embodied and explored have included, among others, crawling, hula-hooping, rolling, jumping, skipping, island hopping, swimming (one of my most popular works is called Chlorine Addiction), drowning, and walking.

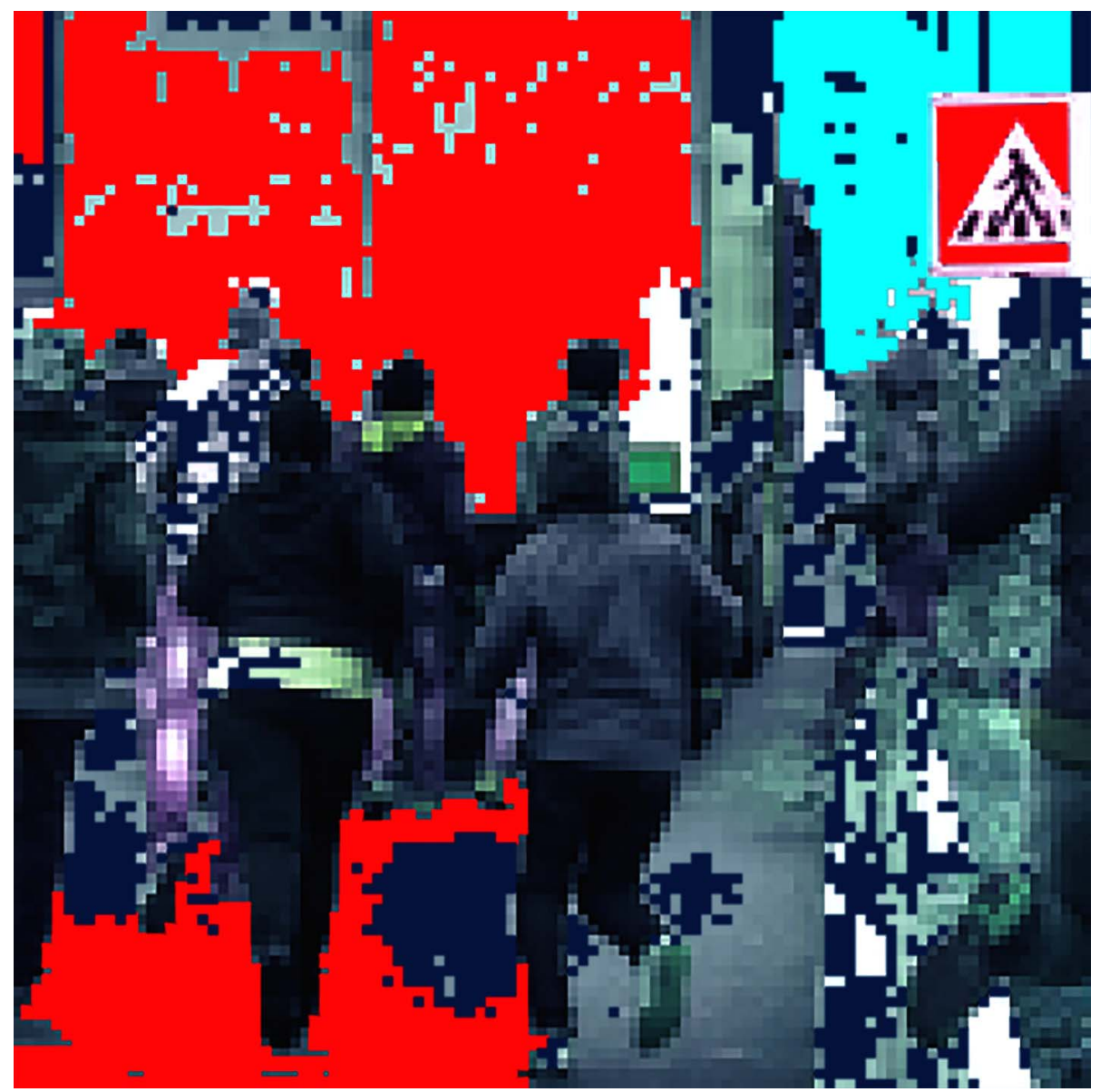

Figure 2: Slide from Prezi titled Bodies on the Run! Run! Run! 2015. A screen capture of a slide from a Prezi, which is a pixelated image depicting migrants running after trucks as a leap to a new life, prezi.com/user/kaisyngtan. Commissioned as performance-lectures in the ANTI Festival (Kuopio, Finland), Exparte (Brick Lane Gallery, London), and Fermynwoods Contemporary Art Centre (U.K.). Image: Kai Syng Tan. 


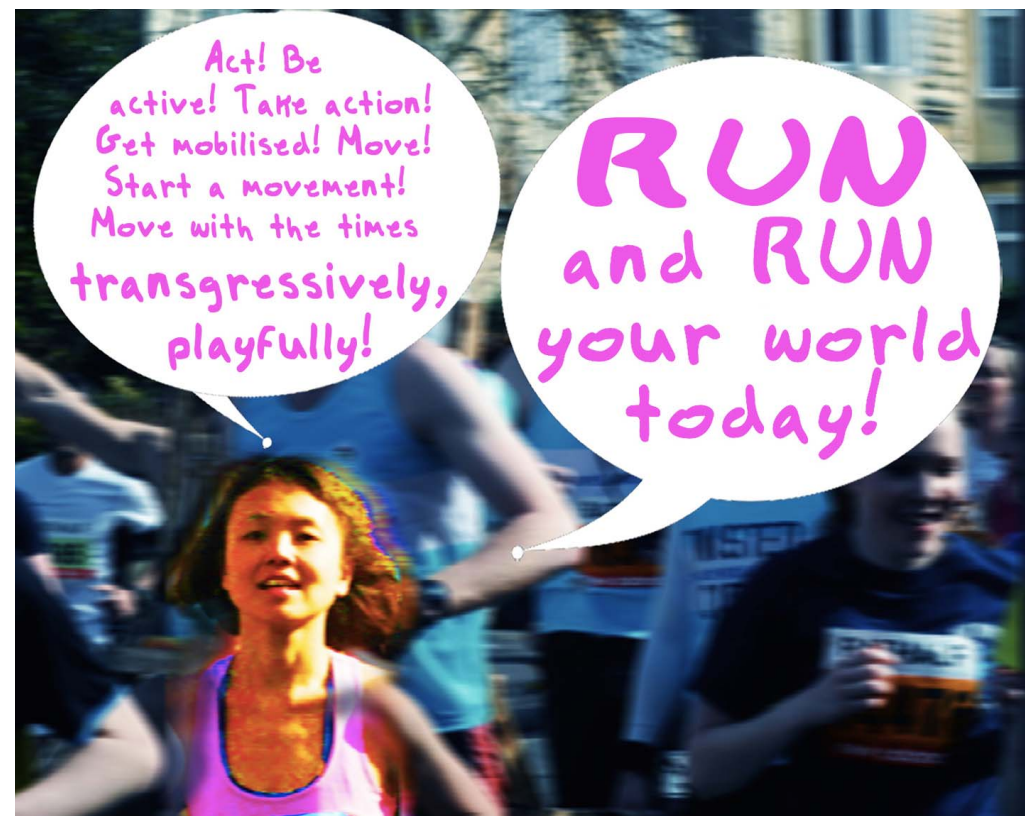

Figure 3: Run, and Run Your World Today! 2012, digital, size variable. Running as a personal, political, poetic, practical, philosophical, and pungent tool of protest. Image: Kai Syng Tan.

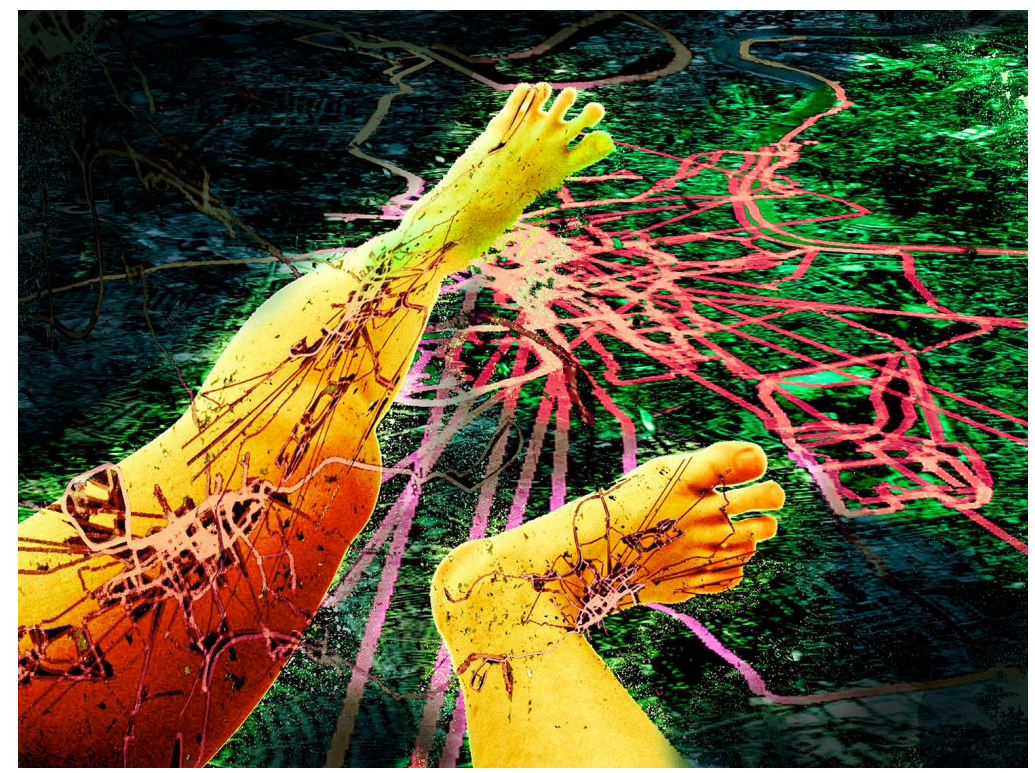

Figure 4: The World as My Body, the Body as My World. 2011, digital, size variable. A visualization of the ancient Chinese Daoist dictum that places the human body as an active interface with society, nature, and cosmos. Image: Kai Syng Tan. 


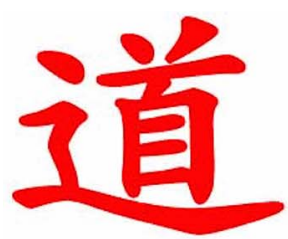

the

Chinese character 'dao'

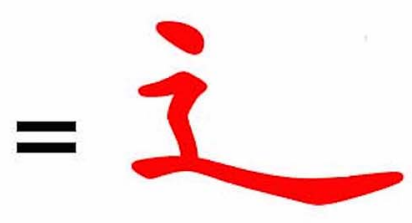

motion verb: of the feet

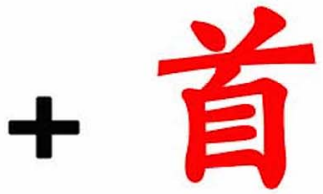

human head

Figure 5: Thinking Is Movement; Stillness Is Death. 2010, digital, size variable. A visualization of the Chinese Daoist philosopher Lao Zi's way or "dao," which Heidegger has described as "poetic thinking." Lao Zi himself as a political exile wandered the world; it was during his life on the move that he wrote the seminal Tao Te Ching. Image: Kai Syng Tan.

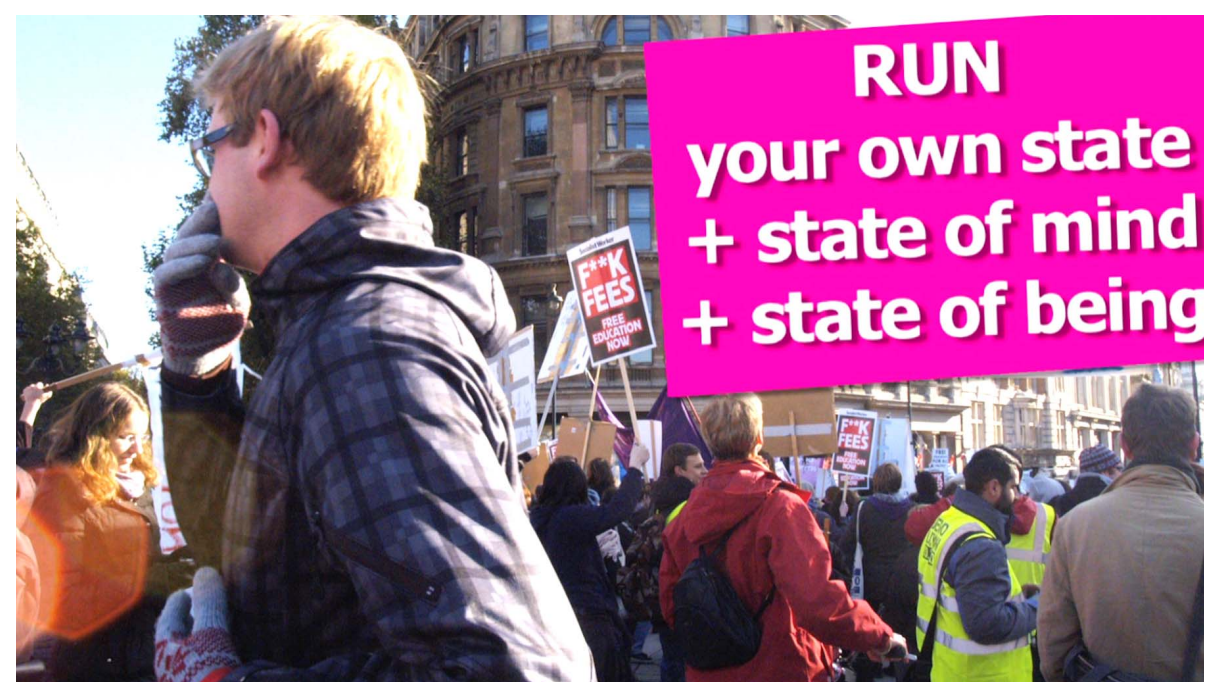

Figure 6: Still from the short film 20 Ways Running Can Change Your World. 2012. Running as a placard, site, sight, and stage of civil disobedience. A trailer of the film can be seen at vimeo.com/87787641. Image: Kai Syng Tan. 


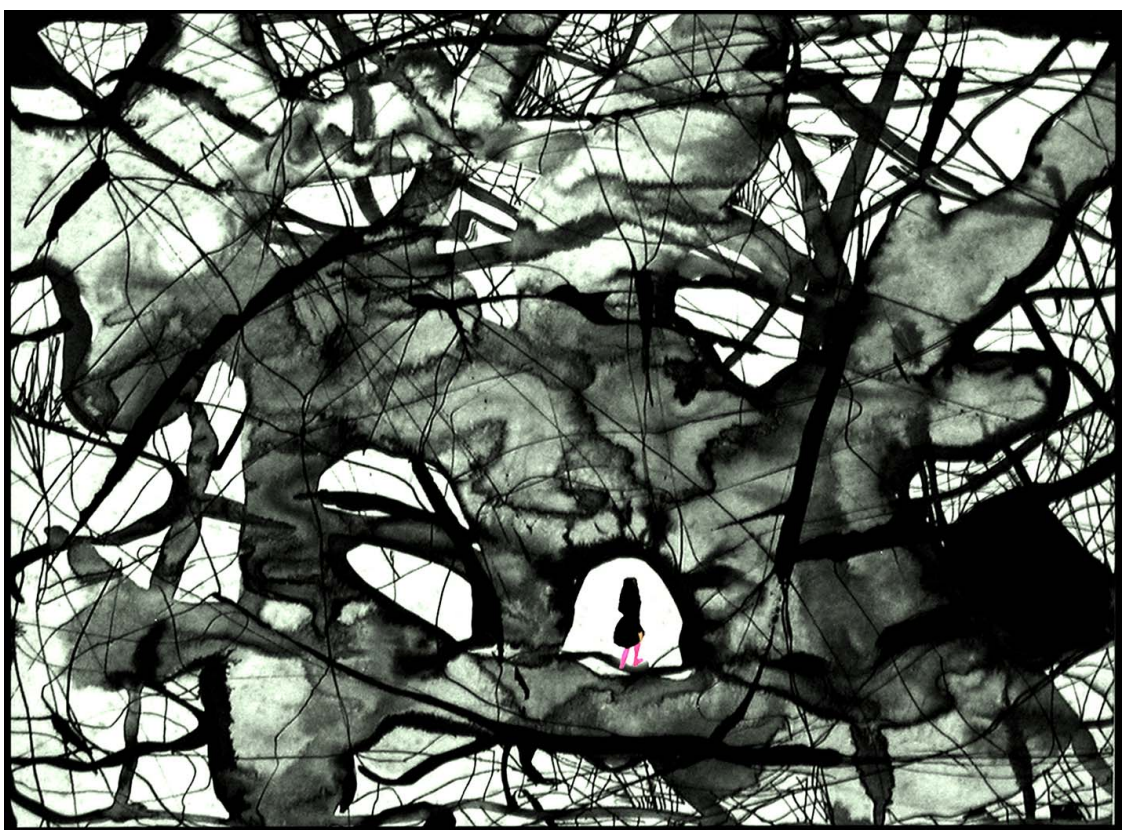

Figure 7: From the series Kaidie's 1000-Day Trans-Run 12.12.2009-09.09.2012. This was a three-year project featuring Kaidie, a fictional runner who traverses terrains urban, digital, imaginary, and cosmic. Here, Kaidie appears as a Second Life figure against an ink drawing background created in 1993. Image: Kai Syng Tan.

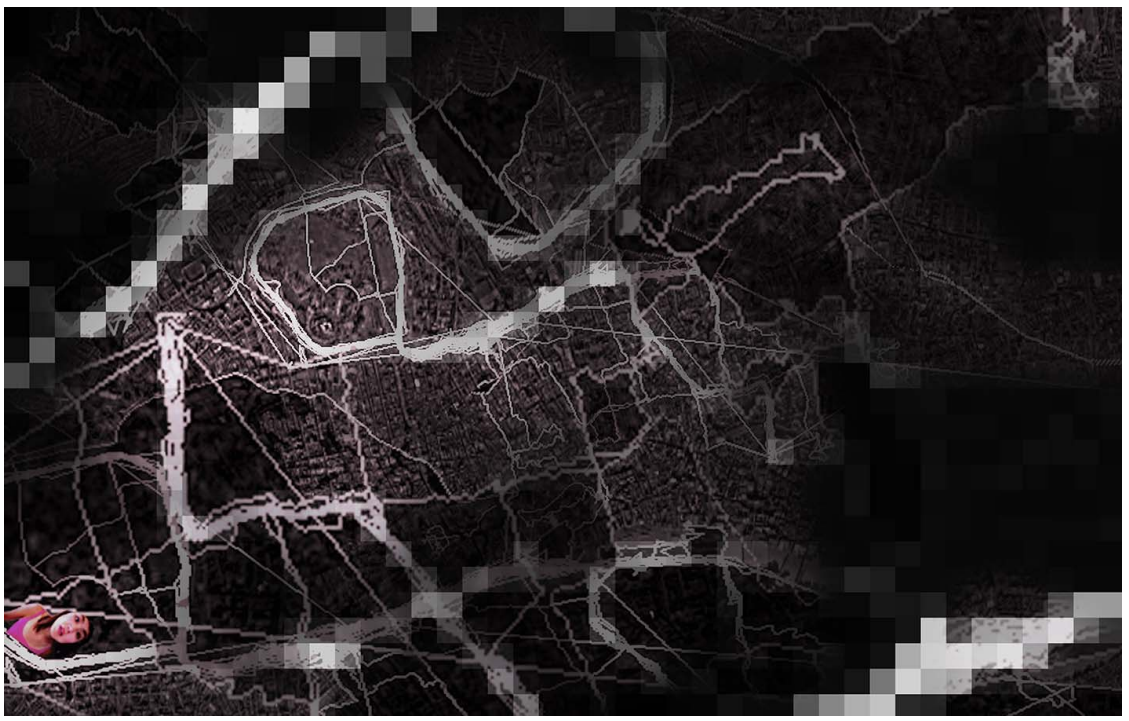

Figure 8: From the series Kaidie's 1000-Day Trans-Run 12.12.2009-09.09.2012. Kaidie looking amazed in a GPS maze of her run in "Nondon," a fictional version of London. Image: Kai Syng Tan. 


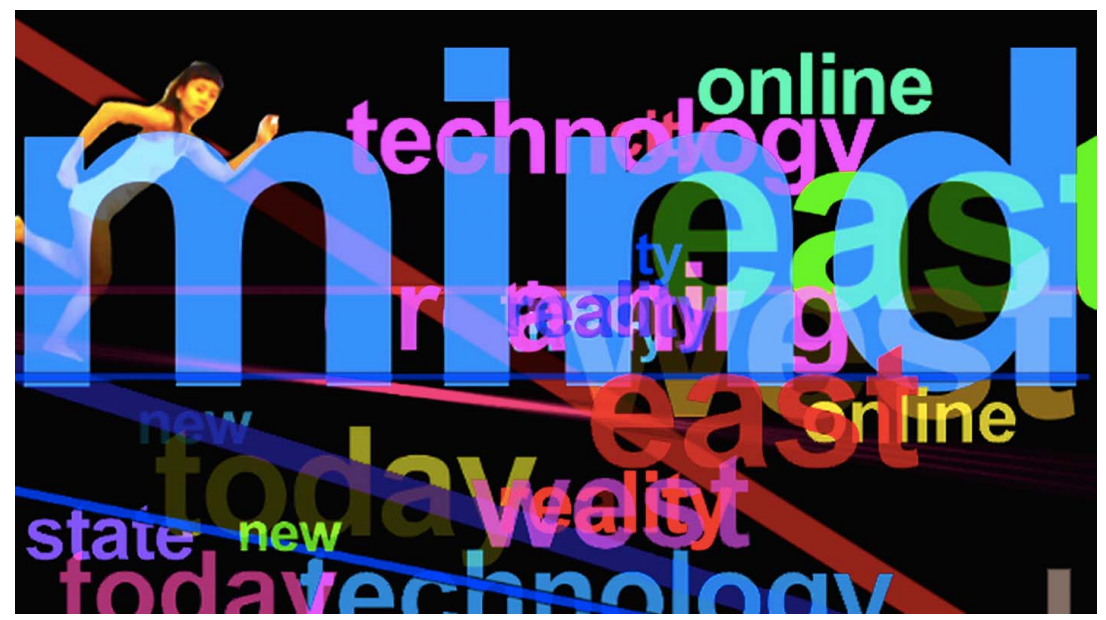

Figure 9: From the series Kaidie's 1000-Day Trans-Run 12.12.2009-09.09.2012. Kaidie traversing conceptual and disciplinary boundaries. Image: Kai Syng Tan.

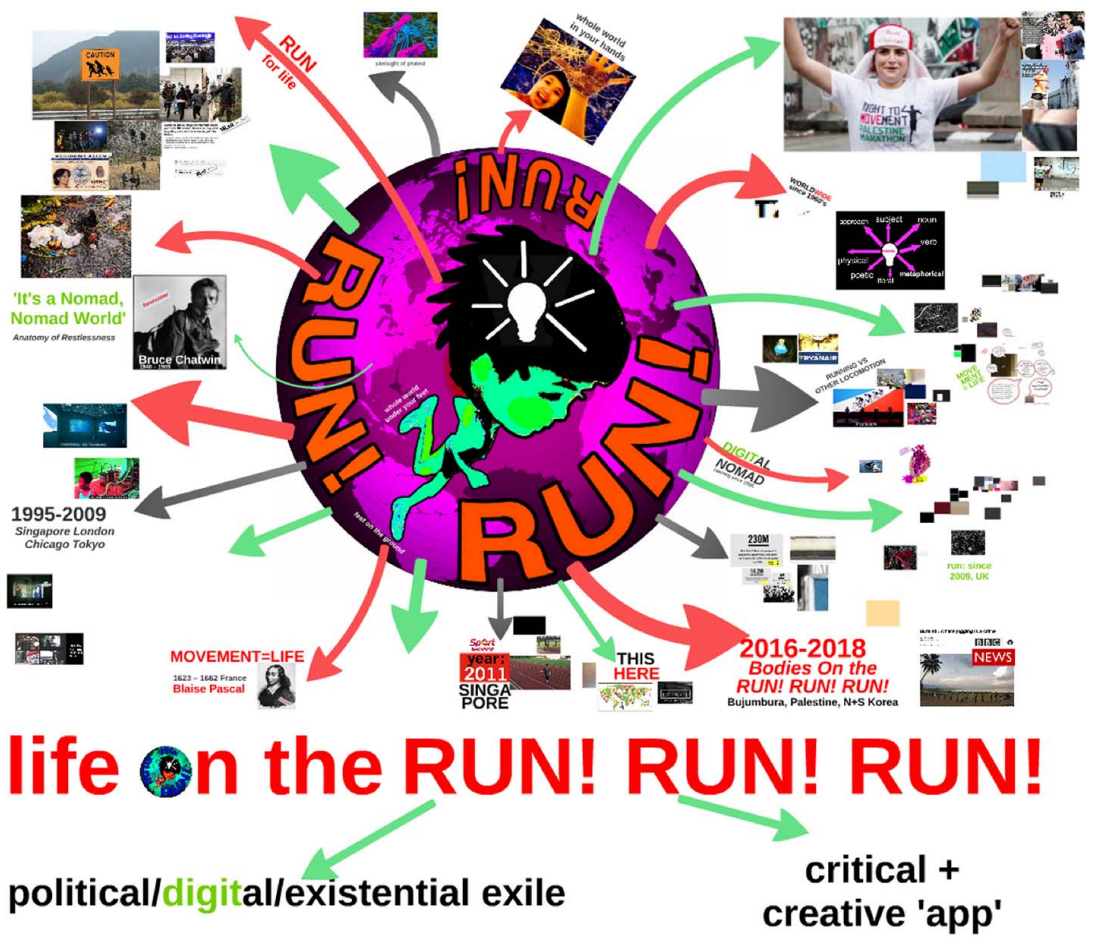

Figure 10: Screen capture of Prezi, Bodies on the Run! Run! Run! 2015. A screen capture of a slide from Prezi, prezi.com/user/kaisyngtan. Commissioned as performance-lectures in the ANTI Festival (Kuopio, Finland), Exparte (Brick Lane Gallery, London) and Fermynwoods Contemporary Art Centre (U.K.). Image: Kai Syng Tan. 
After she became tired of the elite art world and teaching, Kai Syng Tan FRSA returned to the Slade School of Fine Art and completed her PhD. Kai runs the RUN! RUN! RUN! International Body for Research and is a research fellow at Leeds College of Art. E-mail: kai@kaisyngtan.com. www.kaisyngtan.com. 